Res Publica. Revista de Historia de las Ideas Políticas

ISSN: $1576-4184$

\title{
Revolución y Ejemplaridad. El problema de la Idea y su realización. Entre Kant y Arendt
}

Carolina Bruna Castro*

Recibido: 14 de diciembre de 2016 / Aceptado: 11 de diciembre de 2017

Resumen. El siguiente artículo intenta abordar críticamente la relación de las propuestas filosóficas de Hannah Arendt y Kant desde la tensión entre la idea como principio regulador y la acción humana. Para realizar este abordaje consideramos dos textos ejes de Arendt Sobre la Revolución y La vida del Espíritu desde los que analizaremos los conceptos de Revolución, ejemplaridad, nuevos comienzos y Voluntad en debate con la propuesta de Kant.

Palabras claves: Arendt; Kant; revolución; ejemplaridad; voluntad; nuevos comienzos.

\section{[en] Revolution and Exemplarity. The Problem of the Idea and its Realization. Between Kant and Arendt}

\begin{abstract}
This paper attempts an approach in a critic way on the relationship between Hannah Arendt and Kant. To accomplish this I considered particularly two books of Arendt; On the revolution and The Life of the Mind. Considering these books I analyze the concepts of revolution, exemplarity, new beginning and Will in their variance with the original proposal of Kant.
\end{abstract}

Keywords: Arendt; Kant; revolution; exemplarity; will; new beginning.

Sumario: 1. La Revolución. 2. Voluntad y Acción. 3. La persistencia de la idea en Kant.

Cómo citar: Bruna Castro, C. (2018). Revolución y Ejemplaridad. El problema de la Idea y su realización. Entre Kant y Arendt, en Res publica 21.1, 63-75.

Es conocida la referencia a Kant de Arendt a lo largo de su obra. En ella considera al filósofo como un precedente respecto del respeto a la humanidad al mismo tiempo que lo considera, además, uno que no abandono los tópicos importantes que se hallan en la filosofía clásica. Es, también, conocida la crítica que la filósofa establece a la revolución francesa en su texto Sobre la Revolución $(S R)$, desde el cual propone lo que hay que considerar de una Revolución en sentido original, poniendo a la luz su interés por destacar que una tal, debe tener por fin un nuevo comienzo (new beginning), el cual solo se da en la norteamericana. Arendt insiste que un nuevo comienzo necesita reinstaurar un orden, el cual está expresado en las constituciones. Lo que subyace a este interés en los nuevos comienzos se hace manifiesto en su obra inaca-

\footnotetext{
* Universidad de Chile

cbruna@derecho.uchile.cl
} 
bada, La vida del espíritu ( $V E)$, en donde podríamos decir nuevamente, que Kant es un autor siempre presente.

Desde la consideración de estos dos textos en particular, el siguiente escrito pretende mostrar un camino que Arendt reinterpreta desde Kant. Adelantamos que la Revolución tal cual la filósofa la trata queda relacionada con la filosofía kantiana mostrando la posibilidad de que el ser humano construya y reconstruya una visión de mundo que varía. Siguiendo esto, se ha vinculado este hito a lo ejemplar. Ejemplar (exemplarisch) muchas veces se considera en un sentido antiguo, como el que tenía en los textos políticos pre-modernos, que se vincula a la fábula, a la imagen o ejemplo de una figura moralizante o perfecta mediante la cual se educa a la comunidad ${ }^{1}$. Sea desde esta figura moralizante o lo que se ha llamado lo ejemplar negativo, como lo que se debe esquivar ${ }^{2}$ mi propuesta lo dirige al énfasis del gesto subjetivo, que se da con la modernidad, con Kant, que se relaciona con la idea de libertad, que tiene un rol regulador en lo práctico.

Para acercarnos a este problema es menester considerar preliminarmente el reproche que hace Seyla Benhabib en su libro The reluctant modernism of Hannah Arendt. Benhabib destaca varios puntos, en esta propuesta atenderemos a uno de ellos que indica el intento de Arendt por pasar del ámbito de la moral kantiana a lo político, dejando a un lado lo normativo. Creo que en este intento podemos considerar una confusión terminológica que mezcla el sentido de la tradición clásica y el pensamiento moderno. Con esto, en vez de considerar la diferencia entre lo social y lo político propuesta en $S R$-como lo establece McCarty- se debería considerar las lagunas respecto de la normatividad en la medida que las Revoluciones "ejemplifican el genio de encontrar un nuevo orden - a novus ordo saeclorum-"3. Esto, podríamos decir, indica que el problema normativo de Arendt radica en la relación con los principios y su interés por justificar la experiencia como lo fundacional. En el caso de Arendt para enmendar el problema del principio recurrirá a la memoria, memoria que se establece en función con la historia para generar un mito de fundación ${ }^{4}$.

Además preliminarmente debemos considerar que, como se sabe, ya en la propuesta kantiana se muestra que el modo humano de actuar diseñaría una forma de relación con la idea de libertad, que regula la voluntad humana, en la medida que se obliga a la búsqueda del sentido teleológico. Así, una referencia al carácter de ejemplar (Exemplarisch) desde la Revolución es que podemos encontrar varios modos de intentar llevar a cabo la idea, sin que, ninguno de ellos, pueda constituirse como la única regla material, que indique el paso a paso para lograr un resultado al modo de una regla pragmática, sin que ninguno de ellos pueda ser propiamente un ejemplo (Beispiel) a copiar. El concepto de Revolución mostraría su estatuto de aporía que permite poner a la luz dos problemas, uno - particularmente popular por estos días-, el del poder constituyente y la decisión en el cual se encontraría un vínculo entre Arendt y Schmitt ${ }^{5}$. Esto se da en la medida que no hay un fundamento normativo y

\footnotetext{
Se pueden confrontar los ensayos reunidos en A. Gelley et al. Unruly Examples On the rhethoric of Exemplarity, Standford, Standford University Press, 1995.

2 Cf. M. P. Lara, Narrar el Mal, Barcelona, Gedisa, 2009. También, A. Ferrara, La fuerza del Ejemplo Barcelona, Gedisa, 2008.

S. Benhabib, The reluctant modernism of Hannah Arendt,. Maryland, Alta Mira Press, 2003 pp. 156-171. H. Arendt, segunda parte, "La Voluntad", La vida del Espíritu Barcelona, Paidós, 2002. H. Arendt, Sobre la Revolución Madrid, Alianza, 2004, p. 58. Respecto del poder constituyente y el decisionismo, cf. Inter alia A. Kalyvas "From the Act to the Decision: Hannah Arendt and the Question of Decision", en
} 
encontramos una afinidad en la primacía de la acción (decisión). El otro problema que pone a la luz es la distancia entre la idea y la realidad, entre lo práctico y lo pragmático.

En lo que sigue atenderé primero lo que Arendt propone respecto de las revoluciones, luego consideraré algunos puntos de $V E$, concluiré con una breve réplica desde algunos pasajes de la obra de Kant.

\section{La Revolución}

Partiremos recordando que en $S R$ se esboza la crítica que Arendt establece a la Revolución francesa y, desde ella, propone lo que hay que considerar de una verdadera Revolución, poniendo en luz su interés por destacar que esta debe tener por finalidad el nuevo comienzo (new beginning). Al elaborar esta crítica Arendt declara su interés en la Revolución americana, se hace evidente en ella un nuevo comienzo, esto es, la necesidad de reinstaurar un orden, el que para Arendt está expresado en las constituciones y la historia. En este contexto, las constituciones son lo que entendemos a primera vista con este término, esto es, la carta fundamental de una nación. El problema que se irá delineando con el interés de Arendt en las constituciones tiene el mismo sentido que la definición de historia kantiana pero con un matiz importante. Mientras que en Kant la consideración a las constituciones muestra un esfuerzo no completo por regir el mundo desde la libertad, ella las ve como justificación de la acción pura, alejada de la idea. Así, con las revoluciones Arendt ve dos modos de justificación de la experiencia. Por una parte la francesa que pretende realizar una idea, la idea de libertad. Y por otro la norteamericana que partiendo de la experiencia se esfuerza por buscar datos que muestren otras fundaciones similares. Aun cuando encontramos este interés por la experiencia y su recopilación no deja de ser interesante que en otros lugares Arendt apunte a la importancia de considerar los absolutos (ultimates) ${ }^{6}$, de tal modo que refleja su preocupación por un acechante nihilismo.

Con las Revoluciones el orden establecido se quiebra, el curso de los acontecimientos es interrumpido sin dejar de ser algo constituido, al igual que en el terreno de las artes puede cambiar el canon de belleza a la vez que permanecer universal. Así Arendt indica que: "Lo que las revoluciones destacaron fue esa experiencia de sentirse libre (...) Esta experiencia relativamente nueva, nueva al menos para quienes la vivieron, fue, al mismo tiempo, la experiencia de la capacidad del hombre para comenzar algo nuevo"7.

Para Arendt esa experiencia no puede quedar sin justificación, esto deriva del significado original de la palabra Revolución que implica un movimiento que intenta volver a restablecer una estabilidad anterior. Por ello subraya que es importante considerar específicamente a las Revoluciones americana y francesa, ya que ellas

Political Theory, Vol. 32, № 3, Jun., 2004, pp. 320-346. También del mismo Democracy and the Politics of the Extraordinary: Max Weber, Carl Schmitt, and Hannah Arendt, Cambridge, New York, Cambridge University Press, 2008.

6 Declara H. Arendt en una entrevista: “...estoy perfectamente convencida de que toda la catástrofe totalitaria no se habría producido si la gente siguiera creyendo en Dios o, mejor, en el infierno; es decir, si todavía existieran absolutos [ultimates]" (citada por R. Benier en "Ensayo interpretativo" en H. Arendt, Conferencias sobre la filosofía política de Kant, Barcelona, Paidós, 2003, p. 201).

$7 \quad$ H. Arendt, Sobre la Revolución, op. cit. p. 44. 
fueron dirigidas en su etapa inicial por personas que estaban firmemente convencidas, según Arendt:

de que su papel se limitaba a restaurar un antiguo orden de cosas que había sido perturbado y violado por el despotismo de la monarquía absoluta o por los abusos del gobierno colonial. Estos hombres expresaron con toda sinceridad que lo que ellos deseaban era volver a aquellos antiguos tiempos en que las cosas habían sido como debían ser ${ }^{8}$.

Pero para Arendt hay una diferencia fundamental entre las dos Revoluciones, por una parte la revolución francesa significó sentirse libres desde el concepto y por tanto se intentó realizar una idea inexistente; lo que - parafraseando a Nietzsche- llama crear el puente del arcoíris de los conceptos ${ }^{9}$. Muy por el contrario, su hermana, la Revolución americana nació de la necesidad de fundar algo totalmente nuevo, teniendo a la vista la vida pública, recurriendo a la memoria de un pasado remoto, lejano al espacio geográfico donde se instalaba. La Revolución francesa quebró el orden existente en pos de una libertad que era el disfraz de su real origen, a saber, las necesidades sociales ${ }^{10}$. La americana, por su parte, dirigió su gesta a políticas que corresponden a la fundación de un mundo plural, más cercana a los ideales republicanos y a la idea de bien común y felicidad. El énfasis de cada una muestra que la motivación de la Revolución francesa no fue la de la libertad como bien público, proyectar y prometer un mundo común, sino que encontrar el modo de cubrir la falta de vida del individuo, expresando las carencias de los pobres a través de leyes. Así, para Arendt uno de los problemas de la Revolución francesa tiene que ver con la referencia a los sentimientos, a las pasiones, pues no hay distancia de los sentimientos y de la desgracia ${ }^{11}$. Mientras que, la Revolución americana se fundamentó en la idea de éxodo hacia un lugar en el que se realizaría el bien común, para esto se debió inventar un mito fundador. Así, para poder fundar algo nuevo, ante la ausencia de la idea reguladora, se ayudó de la memoria y la historia universal buscando un símil. Así se llegó a la historia de otro pueblo cuyo surgimiento coincide con un éxodo, el éxodo desde Troya, el pueblo, como se sabe, son los romanos. Conviene aquí revisar lo que Arendt relata respecto de los padres fundadores:

Cuando estos hombres de acción, hombres que querían cambiar el mundo, comprendieron que un cambio como este podía, en realidad, entrañar como postulado un nuevo orden del tiempo, el comienzo de algo sin precedentes, empezaron a mirar la historia en busca de ayuda, a repensar monumentos de pensamiento tales

$8 \quad$ Ibidem, p. 58.

9 Dice Arendt en Sobre la Revolución, op. cit., sobre Hegel como icono de esta frase nietzscheana "La idea verdaderamente revolucionaria de Hegel era que el antiguo absoluto de los filósofos se manifestaba a sí mismo en la esfera de los asuntos humanos, esto es, precisamente en ese dominio de las experiencias humanas que, de modo unánime, los filósofos habían descartado como fuente o manantial de las normas absolutas. La Revolución francesa representaba el modelo de esta nueva revelación a través de un proceso histórico y la razón por la cual la filosofía alemana poskantiana ejerció una influencia tan enorme sobre el pensamiento europeo del siglo XX [...] no tuvo nada que ver con su pretendido idealismo, sino, por el contrario, con el abandono de la esfera de especulación pura y con el intento de formular una filosofía que correspondiera y abarcase conceptualmente las experiencias más recientes y reales del tiempo" (p. 69).

$10 \quad$ Ibidem, p. 79.

11 Ibidem, p. 119. 
como el Pentateuco y la Eneida, leyendas de fundación que les podrían decir cómo solucionar el problema del comienzo - un problema porque la verdadera naturaleza del comienzo comporta en sí un elemento de completa arbitrariedad-. Sólo entonces se enfrentaron al abismo de la libertad sabiendo que todo lo que hicieran podría haberse quedado igualmente sin hacer y creyendo, también, con claridad y precisión, que una vez algo está hecho no puede deshacerse, que la memoria humana que narra la historia sobrevivirá al arrepentimiento y a la destrucción ${ }^{12}$.

Ahora bien, ambas revoluciones carecen de idea reguladora que es lo que nuestra propuesta hará notar al destacar algunas lecturas kantianas y la forma en que el filósofo de la ilustración se interesó por los sucesos de su época. Lo que llamó la atención de Kant respecto de la Revolución no fue lo mismo que Arendt apunta, si bien ninguno de ellos tiene la idea de la Revolución como la encarnación de la libertad en el mundo. En la segunda parte de $V E$ Arendt establece algo que ilumina nuestro actual análisis y permite considerar los problemas, en primer término vinculado a lo que ya hemos indicado con el poder constituyente ${ }^{13}$. Lo que digo aun cuando queda ya delineado solo con el acercamiento a $S R$, gana complejidad considerando algunos pasajes de $V E$. Podemos adelantar que en la propuesta de Arendt hay una consideración complicada de lo que es definido por ella como Voluntad (Will).

\section{Voluntad y Acción}

Partamos recordando que Voluntad en la propuesta kantiana se vincula a la idea de Libertad, a la ley, esto es un universal, y tiene un estatuto regulador. Ahora bien, este vínculo presenta siempre una distancia que no puede ser plenamente borrada y, la ejemplaridad muestra simplemente que es posible establecer un tipo de relación desde el particular al universal. La confusión que encontramos en Arendt se hace patente cuando ella define Voluntad como facultad de nuevos comienzos, en la medida que la relaciona con la tradición más bien anglosajona de política que, entiende libertad como posibilidad de actuar. Con esto, Arendt quiere recuperar la noción de Voluntad en un sentido clásico, ella indica que este sentido indica cuando “...una persona era libre si podía moverse como gustase; el criterio era el yo-puedo, y no el yo-quiero"14.

Aunque Arendt considera que las tres facultades a las que dedica su libro VE, a saber, Pensamiento, Voluntad y Juicio, son autónomas entre sí, uno podría argüir una relación que sirve para buscar puntos de apoyo. Respecto al desarrollo de la Revolución que se refiere al nuevo comienzo, estaríamos considerando la Voluntad y considerando operaciones de las otras facultades. Aun cuando para Arendt una de las falacias metafísicas más grandes es la sustitución del Pensamiento por la Voluntad (es decir quitar el puedo dejándola como si fuera una operación meramente interna) su propuesta establece una relación que de algún modo guarda cercanía con el tratamiento moderno ${ }^{15}$. Ahora bien como ya analizamos, llamar nuevo comienzo al gesto de la Revolución americana, no tiene que ver con construir el puente entre idea y

\footnotetext{
H. Arendt, La vida del espiritu, op. cit., p. 441 (Segunda parte la Voluntad).

Cf. A. Kalyvas, Democracy of the extraordinary, op cit., particularmente pp. 194-231.

Ibidem, p.252.

15 Respecto esto, cf. G. W. F. Hegel, Principios de la Filosofia del Derecho, §10, Buenos Aires, Sudamericana, 2004.
} 
realidad, pero podría tener que ver con el ejercicio de Pensamiento en la medida que los padres fundadores son capaces de abstraer su acción para buscar el símil en la historia que les sirve de apoyo y desde el cual fundan lo nuevo ${ }^{16}$.

El argumento de la segunda parte de $V E$, parte de la distinción entre Voluntad (Will), libre arbitrio (liberum arbitrium) (como facultad de escoger faculty of choice) e idea. La facultad de escoger para Arendt está vinculada a un asunto más bien pragmático que estaría siempre funcionando en el plano de los medios en vistas de los fines, además estaría siempre referida a una elección entre solo dos posibilidades. La importancia de esta distinción es el establecimiento de las diferencias entre la posibilidad de nuevos comienzos de los seres humanos y la deducción o inducción lógica de la acción desde principios, según la cual se establecería una operación técnica ${ }^{17}$ que no permite la condición de nuevos comienzos ${ }^{18}$. Evidentemente el tipo de relación que se puede establecer con los principios es aquella que Arendt encuentra en la facultad de Juzgar (apuntada en la última parte inacabada de $V E$ ). Es, cuidando esta relación que Arendt trata de librarse y negar algo que podemos identificar como el signo de la modernidad, estos son los problemáticos absolutos e ideas. El interés de alejarse de los absolutos e ideas es para Arendt un intento por rescatar particularmente la tercera crítica de Kant vinculándola a la voluntad (Will) que para la filósofa se relaciona con la espontaneidad de la razón desarrollada en la primera crítica ${ }^{19}$.

La facultad de la Voluntad, para Arendt, está emparentada con el futuro, con la posibilidad de proyectar y realizar, y, a fin de cuentas, de actuar. En esa medida será una facultad política que contiene el problema de la idea y su realización al relatar su historia. Ella misma define el problema de la siguiente manera:

el problema principal con la Voluntad es que esta no solo opera con cosas que están ausentes para nuestros sentidos y que necesitan hacerse presentes a través del poder que tiene el espíritu para re-presentar, sino también con cosas, visibles e invisibles, que nunca han existido ${ }^{20}$.

Esta referencia a las cosas invisibles que nunca han existido, aunque Arendt lo esquive, sólo puede ser la referencia a la idea. Arendt diagnostica un problema en el giro moderno, reconocido como la búsqueda por entender el mundo a partir de principios, principios que no existen y que son pensados por los filósofos, seres humanos muy alejados de la realidad y la acción. En este contexto, la Voluntad es siempre comprendida bajo los códigos del intelecto, siempre dirigida hacia la contemplación antes que a la acción; siempre normada por un universal antes que por la memoria. De hecho, la memoria como facultad de recurrir al pasado ha perdido aquí todo valor, una experiencia cercana a la que ha tipificado Koselleck con su pasado futuro, la insignificancia de la memoria histórica para adaptarse a un mundo en plena evo-

16 H. Arendt, La vida del espíritu op. cit., primera parte, "El Pensamiento".

17 Recordemos que a Kant le interesa destacar que el tipo de organización a la que se refiere respecto de la acción humana es una moral-practica y no técnico-práctica ver "Introducción" en la Metafísica de las Costumbres, Madrid, Tecnos, 2008.

18 Cf. H. Arendt, "Postscriptum" de la primera parte de La vida del espíritu, op. cit., "El Pensamiento" y también el cap. 7 "La facultad de elegir: proaresis, la precursora de la Voluntad", de la segunda parte "La Voluntad".

19 H. Arendt, La vida del espíritu, op. cit., "Postscriptum" en "El Pensamiento": "La decisión a la que llega la Voluntad jamás puede deducirse de los mecanismos del deseo o de las deliberaciones del intelecto que pueden precederla" (p. 233).

$20 \quad$ Ibidem, p. 246. 
lución. Así, uno de los peligros que corre la Voluntad es quedarse paralizada, que la contemplación le gane terreno a la acción. Esto, según Arendt, es lo que sucede en la mayoría de los tratamientos de la vida del espíritu desde la filosofía y especialmente desde la moderna. Arendt acierta en su diagnóstico respecto de la modernidad como problema, efectivamente, el anhelo de disponer de la estructura del mundo humano implica que, del mismo modo que podemos conseguir predecir ciertas situaciones del mundo natural a través de principios, podemos creer que tenemos en nuestras manos los fundamentos para realizar un mundo desde la teoría. Pero en algo se equivoca, no siempre se puede decir que el pensamiento le gane terreno a la voluntad ya que voluntad siempre implica praxis. Evidentemente, el problema de los sistemas tiene matices y en el caso de Kant persiste la barrera entre teoría y práctica en los asuntos humanos, de tal manera que no se pueden derivar principios prácticos desde los teóricos. Sin embargo, y frente a Kant, lo que hemos comentado en el caso de Arendt es sintomático a su aversión a la norma.

A través de lo dicho antes se vislumbra la cuestión de la relación con la experiencia y la Voluntad. Experiencia es aquí lo vivido por el ser humano tal y como es descrito por la historia. Este punto que, sin duda, lleva la herencia kantiana de modo tal que permite reflexionar sobre la relación entre los seres humanos como comunidad, arrastra profundos problemas. Fundamentalmente, el problema que quiero subrayar en la propuesta de Arendt es una confusión entre Voluntad y potencia (que para la filósofa no es lo mismo que autoridad o fuerza, mandato). Arendt pretende escapar del significado de la libertad de la voluntad como aquel espacio de la vida interior. Ella quiere traer nuevamente el significado de libertad en el sentido clásico, aquel que decía que "una persona era libre si podía moverse como gustase; el criterio era el yopuedo, y no el yo-quiero" 21 . Evidentemente, este planteamiento trae el problema del genio como creación ex -nihilo respecto de esta reinstauración del clásico concepto de libertad como poder que significa actuar y no simplemente desear. Así, Arendt pretende establecer una relación distinta a la moderna entre contingencia y libertad, suponiendo que, para el mundo moderno, la contingencia es un aspecto que no da cabal cuenta de la humanidad, apareciendo siempre a medias y sin nitidez como un fantasma, lo que cruza lo práctico desde lo teórico. Por lo pronto en el contexto de la lectura kantiana que considero, la contingencia no es tanto un fantasma, sino un hecho que se debe aceptar y que genera las aporías que implican el anhelo de alcanzar estabilidad. Sin duda, el conflicto fundamental presente en Arendt es el de la Voluntad y el modo en que el particular actúa. Para ella Kant tiene un lugar especial en la medida en que Voluntad no es diferente de la Razón. Por lo tanto, la voluntad no queda bajo la razón. Como veremos un poco más adelante, lo interesante del análisis de Kant es que, en el ámbito práctico, ningún sistema puede ser construido de modo tal que gobierne el mundo al modo en que un sistema científico puede regir el mundo natural. Así la Voluntad experimenta una tensión en su relación con la memoria -el recurrir humano al pasado- y por eso puede decir Arendt que "Tal tensión solo puede ser superada en la acción, es decir, abandonando completamente la actividad espiritual; dejar la voluntad para tomar el pensamiento no produce más que una parálisis temporal de la voluntad"22.

Ibidem, p. 252.

22 Ibidem, p. 272. 
Así, siguiendo el argumento de Arendt, podemos partir de la diferencia entre voluntad (Will), libre arbitrio (liberum arbitrium) (este como facultad de escoger faculty of choice) e idea. La facultad de escoger para Arendt estaría vinculada a un asunto más bien pragmático en sentido limitado, ya que estaría siempre funcionando en el plano de los medios y no en el plano teleológico, y además estaría siempre referida a una elección entre dos posibilidades. La importancia de aclarar estos términos radica en que se debe distinguir entre por una parte se habla de la posibilidad de nuevos comienzos y natalidad de los seres humanos y por otra de la deducción o inducción lógica de la acción desde principios. Es importante destacar que desde la actividad de esta última se establecería una operación técnica que no permite la condición de natalidad ${ }^{23}$. La condición de natalidad y nuevos comienzos se refiere a la relación que se hace manifiesta en la Crítica del Juicio kantiana en la cuestión del juicio reflexionante frente a la facultad lógica del juicio determinante que estaría más cercano a la deducción e inducción mencionada por Arendt. Siguiendo esta idea la filósofa vincula la Voluntad (Will) a la espontaneidad de la razón desarrollada en la Primera Crítica. Dice Arendt:

Las decisiones que toma la voluntad no se dejan nunca deducir de los mecanismos del deseo o de las deliberaciones del entendimiento que les suelen preceder. La voluntad, o es un órgano de la libre espontaneidad que interrumpe toda cadena causal de la motivación que la pudiera vincular, o, no es sino una ilusión ${ }^{24}$.

Para Arendt, una de las falacias metafísicas es esa que "corresponde al énfasis de la edad Moderna sobre la voluntad como sustitutivo del pensamiento" 25 . Arendt cree que es un problema el que se haya intentado establecer un puente hacia la realidad desde los conceptos, considerando que habitualmente la filosofía ha tratado la Voluntad como subsidiaria del intelecto, como la instancia que pone en práctica sus ideales. Para ella existen ciertos autores que representan otros tantos hitos de un quiebre en este tratamiento. Aquí hay que citar a Agustín de Hipona, Duns Escoto y por supuesto Kant. Bajo la perspectiva de este último, como se sabe, la Voluntad es un modo de la razón, es la razón práctica misma. Continuando este camino Arendt considera que Kant va más allá del tratamiento de la Voluntad como pura contemplación. Ahora bien, para Arendt sigue siendo un problema el que se trate de establecer una suerte de unidad entre lo teórico y lo práctico, la necesidad de terminar escribiendo lo que en verdad es relevante en la Voluntad; esto es, la capacidad de ser un ser humano de acción, tal y como Arendt lo ve en el gesto revolucionario de los padres fundadores norteamericanos. Esto configura un fuerte contraste con lo que se puede decir de la Revolución francesa que es siempre esa relación fallida entre las ideas y la realidad. "La facultad de elegir: proaresis, la precursora de la Voluntad", de la segunda parte "Voluntad".

Este punto es pivotal en nuestro argumento en el sentido de que establece una relación entre Schmitt y Arendt, esta relación a saber sería la de que ambos se sienten motivados por el problema de la decisión sin fundamentos y que se traduce a la acción. Esta idea la maneja A. Kalyvas en su libro (Democracy of extraordinary, op. cit.) y me parece acertada, esto nos indica que el problema que tiene Arendt con los absolutos y que no necesariamente soluciona lo que la atemoriza, el totalitarismo, ya que Schmitt se podría sostener en puntos cercanos. La gran diferencia, como veremos en la parte final, es la relación que establecen los dos autores con la legitimación a la cual agrego sus propios conceptos de Historia o secularización.

24 H. Arendt., La vida del espíritu, op. cit., Postscriptum pensar, p. 244.

$25 \quad$ Ibidem p. 245. 
Pero la propuesta arendtiana corre el riesgo de perder el horizonte, es decir, de que esa nueva noción de la voluntad se vuelva un asunto carente de toda lógica, lo que si bien no lleva a una burocratización si lleva a un problema normativo ${ }^{26}$. Una voluntad sin idea bien puede ser pura acción arbitraria, decisión en sentido schmittiana, pura afirmación existencial.

Para que esto quede más claro es importante destacar además algo respecto del concepto de Libertad que está manejando Arendt. Este concepto, como hemos indicado, pretende recuperar el significado clásico del término, lo que implica separar Libertad de liberación. Liberación tendría un significado individual ya que se refiere a cubrir las necesidades básicas humanas, comer por ejemplo, que son las que están a la base de la Revolución francesa ${ }^{27}$. La libertad, al ser un concepto plenamente político, debe contar con la previa satisfacción de ellas. Luego la libertad no es lo mismo que la voluntad, tampoco es un principio, no es un ultimates. La libertad, dirá Arendt, es algo que simplemente se experimenta y al experimentarse se tiene una idea de ella. Se experimenta en el plano privado como natalidad y en el político como nuevo comienzo $^{28}$. En ambos casos, como veremos, es inicio. Discutiendo kantianamente la relación imperfecta con la idea de Libertad, Arendt demuestra la condición plenamente humana de la necesidad de buscarla.

Podemos decir que Arendt, en cierto modo, está recurriendo a Kant al decir que la libertad no presupone su existencia y que, por lo tanto, no puede ser conocida. La libertad no es distinta de la ley, y es por este sendero que van nuestros problemas e intentos de nuevas derivas. El caso de Arendt es interesante porque tiene una aspiración teórica fuerte a la vez que política, por lo acertado de su análisis a la vez que por lo problemático, y por la necesidad de reconsideración de los puntos en que comete ciertos giros que nos sacan de una lectura apropiada de Kant y que hacen perder conciencia de la distancia entre la libertad en nuestro caso como idea y la realidad. Por su parte, Arendt opera desde los ejemplos, desde la libertad vivida y esto, tiene sus riesgos. Así, la libertad que buscamos, dirá Arendt, fue experienciada en la espontaneidad que es lo propio de la Voluntad ${ }^{29}$. Tomando Agustín de Hipona, dice Arendt: "El hombre puede empezar porque él es un comienzo; el ser humano y ser libre son una y la misma cosa. Dios creó al hombre para introducir en el mundo la facultad de

26 Cf. S. Benhabib, The reluctant modernism of Hannah Arendt, op. cit. Cf. también A. Kalyvas Democracy and politics of Extraordinary, op. cit. Kalyvas propone que Arendt destaca la lectura de Weber contra la burocratización pero siempre trata de arrancar de lo que tenga cercanía con una norma anterior a la experiencia. Kalyvas trata de recuperar Arendt pero para sacarle rendimiento debe recurrir en último término a Habermas. Algo bastante cercano propone Lara introducir la responsabilidad del debate en la narración del mal, ese gesto lo sitúa en Habermas (Cf. M. P. Lara, Narrar el mal, op. cit.).

27 Cf. H. Arendt, “¿Qué es la libertad?” en Entre el Pasado y el Futuro Ocho ejercicios sobre reflexión politica, Barcelona, Península, 1996.

28 Cf. A. Kalyvas Democracy and politics of Extraordinary, op. cit., p. 203. En este lugar el autor destaca el carácter de la libertad como un comienzo absolutamente espontáneo, que requiere fundarse. El Nuevo comienzo como tal podríamos decir que se refiere a dicha fundación.

29 Ibidem. p. 164. Kalyvas en la sección que dedica a Arendt de su libro (Democracy and Politics of Extraordinary, op. cit.) describe muy bien lo que es la libertad para ella: "Libertad, en otras palabras, significa espontaneo «quiebre con los estándares normales para la costumbre cotidiana», durante la cual «instancias singulares y eventos singulares, interrumpen el movimiento circular de la vida diaria en el mismo sentido que el rectilíneo Bíos de los mortales interrumpe el movimiento circular de la vida biológica»" (p.209). [Freedom, in others words, signifies a spontaneous «br[eak] with the normal standars for every day behavior», during which «single instances and single events, interrupt the circular movement of daily life in the same sense that the rectitlinear Bios of the mortals interrupts the circular movement of biological life»"]. 
empezar: la libertad" ${ }^{30}$. Para ella, la libertad política corre un riesgo si se le relaciona con la Voluntad porque llega al resultado de la identificación con poder o mero deseo. En este sentido, dice Arendt: "Políticamente, esta identificación de libertad y soberanía es quizá la consecuencia más dañina y peligrosa de la ecuación filosófica de libertad y libre albedrío..."31. Pero aun cuando Arendt acierta en la identificación de la consecuencia dañina, ella no logra escapar de caer en sus aguas. No en todas las propuestas modernas se realiza esta ecuación. Es en Hobbes donde se establece propiamente, esto mismo no sucede de modo sistemático en Hegel, aunque se pueda ver alguna relación en su teoría del Estado, mucho menos en Kant. Recordemos que para el filósofo de Königsberg. Voluntad se asocia a libertad que es autonomía, que es la posibilidad de actuar movido desde sí mismo, sin ser el títere de nadie, es decir, de ser comienzo, de ser el inicio de la serie causal de las acciones propias ${ }^{32}$. Ser el inicio en una perspectiva kantiana no asegura que este mismo gesto de ser comienzo y origen con implicancia exterior, sea manifestación concreta de las intenciones, como si solo por enunciar las motivaciones, la libertad que impulsa a actuar, sucediera todo lo que ha motivado la acción (lo que ha motivado es su comienzo). Ser inicio no implica lo que se trata de comprobar en la ciencia físico-matemáticas de la época de Kant, a saber, lo que se establece en la ley se da puede comprobar y muestra ciertas estabilidades del mundo natural. Con lo dicho hasta aquí, es importante no olvidar que, en el caso de Kant, como se sabe, la idea de Libertad rige la voluntad teniendo un uso teórico meramente regulativo y por otra parte no tiene un uso constitutivo de la razón especulativa ${ }^{33}$.

Como se sabe la referencia a la facultad de Juzgar, acertadamente rescata como lo subyacente a ella el vínculo entre la facultad del juicio y los objetivos particulares del ser humano, los que contienen algo contingente respecto de lo universal, se pueden pensar respecto de universales al modo inductivo, como juicios determinantes ${ }^{34}$; lo dicho se pone en tensión con un modo de pensar libre, no tematizante, que no es el mismo que el mecánico ${ }^{35}$. La no-tecnicidad, la no-burocratización de la toma de decisión humana, es relevante en la medida que la conexión entre el particular y lo universal no pasa por ser meramente absorbido o presupuesto. Sabemos que esto es así, que es en la tercera crítica en donde se hace presente la difícil relación entre el sujeto particular y las ideas que ya no son reguladoras al modo de la Crítica de la razón práctica, sino que se refieren a la capacidad del ser humano de proponer una regla universal. Sabemos que, lo que Kant propone en la Crítica del Juicio (CJ) es la posibilidad de un tipo de juicio que, desde lo particular, puede arribar a una propuesta universal, es decir, que pueda tener un estatuto normativo no inductivo y que pueda avanzar sin conceptos previos. Kant lo definirá a través de la capacidad del genio (artista) de proponer una obra ejemplar, en este contexto acuña el concepto

$30 \quad$ H. Arendt., “¿Qué es la libertad?”, op. cit., p. 180.

31 Ibidem, pp. 176-177.

32 Esto es así incluso para Hegel que sirve de base para muchos que se ocupan de a teoría de la acción. Se puede cf. Los principios de la filosofía del derecho, op. cit., §10 y $\S \S 105-128$. La soberanía se referiría particularmente a la autoridad del príncipe y no se refiere a la posibilidad de comenzar que es lo que estamos tratando aquí. Agradezco para este tratamiento la gentileza del Prof. Giuseppe Duso que me permitió asistir a su seminario sobre la filosofía del derecho de Hegel en la Università degli studi de Padova el semestre de primavera del 2012. I. Kant, Metafísica de las costumbres, op. cit. pp. 26-27.

H. Arendt, La vida del espiritu, op. cit., “Apéndice/ El Juicio”, pp. 453-469.

35 Este punto tendría que ver especialmente con el problema de la historia en Kant y la naturaleza. La misma Arendt lo indica así en sus Conferencias sobre la filosofía politica de Kant, op. cit. 
de ejemplaridad (Exemplarish) ${ }^{36}$. El problema con Arendt será considerar que es en la espontaneidad de la razón como un estatuto alejado de la idea, que se debe dar el nuevo comienzo.

Por lo tanto, aunque la lectura que Arendt hace de Kant, es realmente próspera, dado que muestra un movimiento antropológico-político que pone en evidencia la posibilidad autonormativa del ser humano más allá de seguir hábitos y patrones pre establecidos, en su interés por despejar la variable de la idea, no considera la posición de la libertad entre ella y el arbitrio. Idea que, al fin y al cabo, permite indicar que no es un asunto simplemente biológico el de los nuevos comienzos, alzándose como aquello que está en vínculo con la capacidad humana de juicio. He indicado que el interés de Arendt al proponer esto es evitar el totalitarismo. Pero, el totalitarismo se entiende de la mano del concepto de soberanía y no del de libertad que es lo que estaría a la base de la propuesta kantiana y para Kant estos dos conceptos no son lo mismo. Con esta confusión ella podría caer en lo que tanto intenta evitar ${ }^{37}$. Si pensamos en la distinción kantiana de voluntad y arbitrio, la Voluntad siempre quedará sobre el arbitrio precisamente por tener una cercanía con la idea de Libertad, mientras que el arbitrio permanecería siempre más ligado a la acción. Entonces, si bien Arendt cree que, esquivando los absolutos evita el Totalitarismo, ha pasado por alto que el Totalitarismo no se basa estrictamente en absolutos, sino que requiere hacer pasar por absolutos aspectos contingentes, si bien requiere generar un puente entre algo abstracto y realidad, no necesariamente es una idea sino que son valores que bien pueden ser intereses privados ${ }^{38}$. Así, los mitos fundadores pueden suplir la función de las ideas abstractas, respecto de ello la secularización es un modo de cristalizar este gesto.

\section{La persistencia de la idea en Kant}

En primer lugar recordemos que Kant en su Metafísica de las Costumbres (MC) considera tanto al arbitrio como a la voluntad en relación con la facultad de desear. Facultad de desear "es la facultad de ser, por medio de sus representaciones, causa de los objetos de estas representaciones. La facultad de un ser de actuar según sus representaciones se llama vida" 39 . Con solo considerar estas afirmaciones ya tenemos algo que discutir con Arendt, esto sería que, en cuanto el arbitrio tiene una relación con la voluntad estarían ambos vinculados a los apriori kantianos. El ser humano cuando realiza algo tendría la posibilidad de error a través del arbitrio ya que no es la idea pura sino que sus representaciones, esto es, modos de intentar dar forma al mundo contingente motivado desde la idea ${ }^{40}$. Es por eso que la experiencia no podría ser la fuente de la ley, ni tampoco la historia. Kant en $C J$ se preocupó de mostrar que en los asuntos morales no hay una teoría que explique cómo son las cosas, sino el modo

\footnotetext{
36 I. Kant, Crítica del Juicio, Madrid, Austral, 2001, §46, 47.

37 Cf. A. Kalyvas Democracy of extraordinary, op. cit.

38 Cf. C. Schmitt, La tiranía de los valores, Buenos Aires, Hydra, 2009, "La idea requiere mediación el valor aún más", p. 49.

39 I. Kant, Metafísica de las Costumbres, op. cit., p.13.

40 Este punto permite profundizar en los nexos Arendt-Schmitt considerando la preeminencia de la Idea, aunque no es sobre Arendt ni Kant, se puede ver G. Duso "La Rappresentazione e 1'Arcano dell'Idea" en Il Centauro Rivista di filosofia e teoria politica settembre-dicembre Napoli, Guida editori, 1985, pp. 35-70.
} 
en que se establece una reflexión desde el sujeto. Con esa aclaración muestra que la cercanía del ser humano a la ley siempre va dando muestras de una carencia, o mejor de un acabamiento imperfecto. Por tanto no puede sacarse la ley de una experiencia individual en la medida que puede ser equivocada, pues no hay ejemplo de la realidad perfecta de la idea ${ }^{41}$. En la Introducción a la Metafísica de las Costumbres el objetivo es mostrar que la moral no tiene por origen los sentimientos del espectador, ni el deseo. Kant al definir vida como la facultad de existir por medio de las representaciones, distinguirá entre voluntad (Willen) -Deseo (Lust) y arbitrio (Willkür). La voluntad apunta a los fundamentos de la Razón (Vernunft) de la determinación de la acción, el arbitrio a la unión a la conciencia de ser capaz de producir el objeto mediante la acción y la ausencia de esta unión se llama deseo. Así podríamos decir que el arbitrio es la manifestación de la voluntad en la acción, la cual por cierto es imperfecta ${ }^{42}$.

Continuando con la $C J$ podemos pensar el caso de la Revolución para entender qué trató de ver Kant en ella. Kant tiene una idea de la revolución francesa que la liga a los problemas de la organicidad trabajados en la $C J(\$ 65)$. La idea de organicidad dice relación con la teleología del ser humano, hace evidente que este se considere un fin en sí mismo y con ello a toda la humanidad, por tanto con esto se puede considerar al ser humano y sus asociaciones -mejor comunidades-. Es el estatuto de ser humano como un ser que puede darse sus propios fines, incluso contra lo que la naturaleza propone, la posibilidad de darse sus propios fines y buscar su propia forma es lo que Kant logra ver en la revolución. Kant dirá que un ser humano es: "Un ser organizado, pues, no es solo una máquina, pues esta no tiene más fuerza formadora, y tal, por cierto, que la comunica a las materias que no la tienen (las organiza), fuerza formadora, pues que se propaga y que no puede ser explicada por la sola facultad del movimiento (mecanismo)" "43.

Con esto, la Revolución francesa es puesta como momento ejemplar, pero esto no quiere decir que sea una norma a seguir, tampoco quiere decir que refleje el universal en modo tal que sea válido en todo tiempo y lugar para ser aplicado, no es una encarnación de la idea de libertad, mucho menos de la buena Voluntad. Arendt remarcará que el punto puesto en relieve es el constitucionalismo de Kant como forma de nuevo comienzo. Creo que el asunto desde Kant puede referirse simplemente a la tendencia hacia la idea sin que signifique el momento de cristalización del poder, que podría entenderse de la mano de un constitucionalismo y la acción ${ }^{44}$. Por tanto, este momento solo nos muestra, lo que es la organicidad, esto es la dependencia de la parte y el todo. Muestra a la vez el desarrollo del género humano intentando desplegar algo que se ve obstruido en su realización, busca la paz, busca la libertad que no están, pero queda en eso, en la búsqueda.

Podemos entrar un poco más en este caso, pero ya no considerando meramente la referencia a la $C J$. Como se sabe, en principio, Kant no está de acuerdo con los

41 Respecto de que la idea siempre permanece sobre las experiencias, esto estoy de acuerdo con Giuseppe Duso que propone que en la propuesta kantiana se vería una excedencia de la idea de libertad. Cf. Idea di Libertà e costituzione republicana nel pensiero di Kant. Un itinerario attraverso i testi, Padova, Libreria editrice, Università di Padova, 2004.

42 I. Kant, Metafísica de las Costumbres, op. cit., pp. 13-17.

43 I. Kant, Crítica del Juicio, op. cit., p. 346. Cf. también la nota al §65, p. 347

44 Para Arendt esta referencia muestra el constitucionalismo kantiano. Cf. segunda Conferencia en Conferencias sobe la filosofia politica de Kant, op. cit., pp 28-39. Respecto a esto ya nos hemos referido más arriba. 
levantamientos y revoluciones ${ }^{45}$. Esto pues, el filósofo supone una constitución republicana y ser súbdito de ella implica tener asegurado en alguna medida los derechos, al menos el único innato: la posibilidad de ser el propio señor, i.e. la libertad. Como sabemos esto no se realiza constantemente y para Kant si un Estado no es perfecto, al menos asegura la paz y por tanto, cualquiera es mejor que ninguno. Si bien un Estado concreto no es la idea efectuada, tampoco tendrá la característica de ser una máquina que funciona ciegamente, muy por el contrario, si podemos hablar de la historia y ella es el transcurso del derecho positivo es porque los vínculos sociales son perfectibles, se mueven hacia la idea de libertad $^{46}$. Los malentendidos, la mala interpretación es parte del choque entre los principios y el mundo. Regular la resistencia es regular lo que no tiene medida.

Con esto, la experiencia de la libertad que muestran las revoluciones es relevante solo en cuanto, tentativa de pasar de alcanzar la idea por la acción y como se sabe, en Kant la idea no se concreta, no se hace efectivamente real, porque la libertad no necesariamente existe. El aspecto normativo permanece en la esfera de la voluntad, mientras que todo lo demás se refiere al arbitrio. Por eso no solo las revoluciones nos muestran esa carencia de la idea reguladora, y también de los modos de gobernar. Las revoluciones son el hecho más conflictivo ya que desde su propia definición se quieren acción transformadora y esa acción transformadora puede perder el punto de orientación, la idea de libertad.

45 I. Kant dice en el apartado "Contra Hobbes" de "Sobre el tópico esto puede ser en la teoría pero no vale para la práctica” en En defensa de la Ilustración Barcelona, Alba, 1999: “...toda oposición contra el supremo poder legislativo, toda incitación a vías de hecho del descontento de los súbditos, todo levantamiento que estalle en rebelión, es el delito supremo y más punible en la república, pues destruye sus fundamentos” (p. 271).

46 Cf. Y. Yovel, Kant and the Philosophy of History, New Jersey, Princeton University Press, 1985. En la misma línea con matices cf. J. L. Villacañas, "Naturaleza y razón: Kant filosofo del clasicismo" en Villacañas, J. L. Bozal, et. al., Estudios sobre la "Crítica del Juicio”, Madrid, La Balsa de la Medusa, 1990, pp. 13-74. 